\title{
Actions now can curb food systems fallout from COVID-19
}

\author{
COVID-19 is disrupting food systems globally and governments must stabilize food supply chains and thoughtfully \\ expand social safety nets now to avert social unrest. Lessons learned from the 2008-2012 food price crises point to \\ seven actionable points to consider.
}

\section{Christopher B. Barrett}

M ajor food supply chain disruptions have been a catalytic feature of many historical conflicts - such as the French Revolution and the Arab Spring - leading to social unrest and violence. When global food prices jumped in 2008 and again in 2011-2012, consumers took to the streets and food riots broke out in roughly 50 countries $^{1,2}$. Some of these riots turned violent, contributing to the overthrow of governments in Haiti and Madagascar, for example. If demand outstrips supply and carryover stocks run too low, it can ignite speculative activity that the food supply chain cannot satisfy; then food prices spike ${ }^{3}$.

The COVID-19 pandemic is already disrupting food supply chains. The good news is that we are not near the point of prices spiking. To date, harvests have been largely undisturbed by COVID-19, and this is likely to continue over the coming months. The best forecasts for major staple crops suggest good upcoming harvests in places where the growing season is in progress ${ }^{4}$. But an important exception exists - the massive locust infestation currently plaguing East Africa continues to threaten food security in the region, where the pandemic complicates efforts to contain the pests in a region where $10-20$ million people were already food insecure ${ }^{5}$.

The Food and Agriculture Organization of the United Nations (FAO) food price index - a summary of prices across commodities in global markets - has now fallen more than $25 \%$ below its 2011 high in inflation-adjusted terms, and fell almost $6 \%$ from January to March this year ${ }^{6}$. Furthermore, oil prices have fallen - for reasons largely unrelated to coronavirus - and are likely to remain low as people travel less and fuel demand thus decreases. This assists in keeping food prices down as energy costs are a significant component of retail food prices. However, the FAO food price index is also almost 7\% higher than its 2007 level before the series of destabilizing price spikes began in 2008 (ref. ${ }^{6}$ ). If lockdowns begin to seriously disrupt agricultural labour forces in India (where the winter harvest is just beginning), Brazil and ultimately the United States, the European Union, China, Canada and other major exporting regions in the Northern Hemisphere, then we should expect a drop in farm-level production that could put upward pressure on prices later in the year.

In the short term, COVID-19 challenges the post-farmgate value chain that accounts for roughly three-quarters of the cost of food worldwide (about $85 \%$ in the US) (ref. ${ }^{7}$ and J. Yi et al., unpublished observations). Retailers' empty shelves arise not because of farm-level production shortages, but rather because of a temporary rush as consumers stockpile certain products - toilet paper, eggs, frozen vegetables - creating a brief blip in demand, but far beyond normal throughput volumes. The supply chain can easily backfill and replenish shelves as long as it is allowed to operate as normal. The system stabilizes quickly if processors can mill and manufacture foods; bottlers can produce beverages; trucks, trains, ships and planes can move products to distribution centres and stores; and workers are available to manage all these steps. Perishable food prices will provide a warning signal for future price spikes, especially between June and August 2020 when labour and transport bottlenecks may emerge as the main Northern Hemisphere harvests begin.

The greater risk for food insecurity and social unrest comes not from the supply, but from the demand side. The measures taken to safeguard public health are prompting an unusually large and rapid economic contraction. Unprecedented numbers of people are losing their jobs, businesses and livelihoods. As COVID-19 begins to impact low- and middle-income economies, the rise in poverty, food insecurity and malnutrition will be serious.

\section{Seven steps to avoid social unrest} To avoid social unrest, we must learn the lessons of the 2008 and 2011 food price spikes $^{1}$. Fewer people took to the streets and violence rarely surfaced in countries where governments and civil society worked together to provide effective social safety nets to help people feed their families when incomes fell and prices spiked. In the present context, protecting public health and providing a comprehensive safety net in which people have confidence are crucial - governments and businesses that support the people are in turn supported by the people. Historical and economic research on this topic provides several key policy lessons.

Healthy workforce. Workers - even temporarily unemployed workers - must be kept physically healthy. Even highly mechanized food systems will slow to a crawl if too many people fall sick or die. Public health experts' guidance is crucial - if they tell us to test, trace and stay home until health systems can manage COVID-19, as they routinely do other viruses, then we must all follow that advice.

Economic safety nets. The emergency funding that many high-income country governments have enacted is a step in the right direction, but more aid that is better targeted at those most in need will be required in the coming months. Governments of high-income countries must expand support for vulnerable populations in low- and middle-income countries, as the International Monetary Fund did by providing debt service relief for 25 low-income countries ${ }^{8}$. Without this, there will probably be another surge of refugees and forcibly displaced people at a time when we are already witnessing the highest-ever recorded levels of displacement - with more than 70 million people affected ${ }^{9}$. This will further destabilize 
border regions and cause unspeakable human suffering.

Interest rates are at historic lows. This is the best time to borrow, if and as needed, to protect the global community from hunger and social unrest. This task falls not just to governments, but also businesses and private citizens that maintain high incomes and can donate generously to health care providers and first responders, as well as to civil society organizations - food banks, food pantries, humanitarian relief organizations, and so on - that protect our health and our food security.

Redeploy workers. Food supply chain workers are 'unsung heroes', putting themselves at risk to meet the essential daily needs of others. Grocery chains are frantically hiring to expand delivery, restocking, custodial and food preparation teams. Governments could save on unemployment insurance payments by subsidizing temporary hiring in essential industries, including in health and food systems. Public works programmes ideally supported by a standing employment guarantee - can also serve this function. Once antibody testing permits identification of those who appear to be at least temporarily immune to coronavirus, healthy workers can enhance food supply chain function, especially in serving the most vulnerable: the elderly, the homeless, shut-ins and the hospitalized, schools and prisons. An expanded institutional food service for the vulnerable, staffed by healthy workers, can also help absorb perishable commodity supplies currently being lost as bulk processing for non-retail outlets has collapsed amid lockdowns. This would also reduce farmers' losses.

Voluntary limits on essential goods. Retailers can limit the sale of essential goods - toilet paper, eggs, frozen foods, pasta and similar staples - to manage herd behaviours that temporarily disrupt supply chains. Individual consumers also need to exercise self-restraint by not buying so many perishables, and by being cognizant of food spoilage and waste. Consumer food waste, which already ranges from 9-37\% for perishables ${ }^{10}$, could easily jump with panicked stockpiling if not well managed through voluntary purchase limits.

Migration. The advice from pandemic experts on how best to manage the movement of people must be followed. However, we must also be aware of governments using temporary measures as a cover to enact longer-lasting immigration restrictions for nationalist, rather than public health, purposes. Tighter restrictions on migrant workers will ultimately disrupt farm-level production and post-farmgate processing and distribution, leading to higher prices by the end of 2020, and potentially to social unrest in some places. It will also accelerate the replacement of workers with robots and other automation, aggravating underlying labour market and income inequality issues.

Avoid protectionism. Governments must not repeat the protectionist errors of the 2008-2012 period, when many enacted export bans to try and trap domestically produced food for their own citizens and temporarily drive domestic prices back down. This largely backfired ${ }^{11}$. World Trade Organization initiatives and other trade agreements are not designed to impede export bans, so we rely on global leaders to exercise self-control. A few governments that restricted exports a decade ago Kazakhstan, Russia, Ukraine and Vietnam - are implying similar actions now or have begun to implement food export controls. Meanwhile, a few governments, including the US, are temporarily reducing import tariffs. More than $70 \%$ of food worldwide is eaten in the country in which the source product was grown ${ }^{12}$, but we rely heavily on trade to stabilize market prices and avoid price spikes.

Punish profiteering. Price gougers and those engaged in unfair trade practices must be vigorously tracked and prosecuted. Companies that make extraordinary profits by exercising market power during a crisis should be penalized to the maximum extent allowable by law and publicly shamed where legal loopholes protect them. Many jurisdictions have anti-profiteering laws against unjustified increases in prices of essential goods and need only to publicly enforce the law. Places without such laws can readily and quickly adapt the laws of others to their own context.

Social unrest arises in places where governments fail to provide adequate social safety nets, where their decisions and the decisions of their favoured firms are perceived as unfair, corrupt or irresponsible. The most important duty of the state is to protect its citizens from harm. Although the risks of social unrest are negligible in most of the world, in regions where citizens already have substantive grievances, missteps cause added harm and the risk of social unrest becomes a greater threat as the COVID-19 pandemic continues and risks greater disruptions to food systems.

\section{Christopher B. Barrett (D) $₫$}

Charles H. Dyson School of Applied Economics and Management, Cornell University, Ithaca, NY, USA.

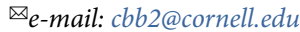

Published online: 7 May 2020

https://doi.org/10.1038/s43016-020-0085-y

References

1. Barrett, C. B. Food Security and Sociopolitical Stability (Oxford University Press, 2013).

2. Bellemare, M. F. Am. J. Agric. Econ. 97, 1-21 (2015).

3. Wright, B. D. Appl. Econ. Perspec. Policy 33, 32-58 (2011).

4. Cereal Supply and Demand Brief (UN FAO, accessed 2 April 2020); http://www.fao.org/worldfoodsituation/csdb/en/

5. Desert Locust (UN FAO); http://www.fao.org/locusts

6. UN FAO Food Price Index (UN FAO, accessed 2 April 2020); http://www.fao.org/worldfoodsituation/foodpricesindex/en/

7. Reardon, T., Bellemare, M. F. \& Zilberman, D. How COVID-19 may disrupt food supply chains in developing countries. International Food Policy Research Institute Blog https://go.nature. com/2yWlgil (2 April 2020).

8. IMF executive board approves immediate debt service relief for 25 eligible low-income countries. International Monetary Fund https://go.nature.com/3d296X1 (15 April 2020).

9. Figures at a Glance (UNHCR, 2020); https://www.unhcr.org/ en-us/figures-at-a-glance.html

10. The State of Food and Agriculture: Moving Forward on Food Loss and Waste Reduction (UN FAO, 2019).

11. Anderson, K. Glob. Food Secur. 1, 157-166 (2012).

12. D'Odorico, P. et al. Earths Future 2, 458-469 (2014).

Competing interests

The author declares no competing interests. 